NASA/TM-2002-210731

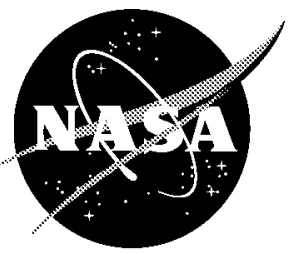

\title{
The Aircraft Simulation Role in Improving Flight Safety Through Control Room Training
}

Karla S. Shy, Jacob J. Hageman, and Jeanette H. Le

NASA Dryden Flight Research Center

Edwards, California 


\section{The NASA STI Program Office...in Profile}

Since its founding, NASA has been dedicated to the advancement of aeronautics and space science. The NASA Scientific and Technical Information (STI) Program Office plays a key part in helping NASA maintain this important role.

The NASA STI Program Office is operated by Langley Research Center, the lead center for NASA's scientific and technical information. The NASA STI Program Office provides access to the NASA STI Database, the largest collection of aeronautical and space science STI in the world. The Program Office is also NASA's institutional mechanism for disseminating the results of its research and development activities. These results are published by NASA in the NASA STI Report Series, which includes the following report types:

- TECHNICAL PUBLICATION. Reports of completed research or a major significant phase of research that present the results of NASA programs and include extensive data or theoretical analysis. Includes compilations of significant scientific and technical data and information deemed to be of continuing reference value. NASA's counterpart of peer-reviewed formal professional papers but has less stringent limitations on manuscript length and extent of graphic presentations.

- TECHNICAL MEMORANDUM. Scientific and technical findings that are preliminary or of specialized interest, e.g., quick release reports, working papers, and bibliographies that contain minimal annotation. Does not contain extensive analysis.

- CONTRACTOR REPORT. Scientific and technical findings by NASA-sponsored contractors and grantees.
- CONFERENCE PUBLICATION. Collected papers from scientific and technical conferences, symposia, seminars, or other meetings sponsored or cosponsored by NASA.

- SPECIAL PUBLICATION. Scientific, technical, or historical information from NASA programs, projects, and mission, often concerned with subjects having substantial public interest.

- TECHNICAL TRANSLATION. Englishlanguage translations of foreign scientific and technical material pertinent to NASA's mission.

Specialized services that complement the STI Program Office's diverse offerings include creating custom thesauri, building customized databases, organizing and publishing research results...even providing videos.

For more information about the NASA STI Program Office, see the following:

- Access the NASA STI Program Home Page at http://www.sti.nasa.gov

- E-mail your question via the Internet to help@sti.nasa.gov

- Fax your question to the NASA Access Help Desk at (301) 621-0134

- Telephone the NASA Access Help Desk at (301) 621-0390

- Write to:

NASA Access Help Desk

NASA Center for AeroSpace Information 7121 Standard Drive Hanover, MD 21076-1320 
NASA/TM-2002-210731

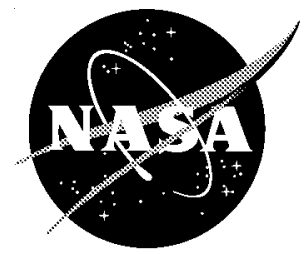

\section{The Aircraft Simulation Role in Improving Flight Safety Through Control Room Training}

Karla S. Shy, Jacob J. Hageman, and Jeanette H. Le NASA Dryden Flight Research Center

Edwards, California

National Aeronautics and

Space Administration

Dryden Flight Research Center

Edwards, California 93523-0273

August 2002 


\section{NOTICE}

Use of trade names or names of manufacturers in this document does not constitute an official endorsement of such products or manufacturers, either expressed or implied, by the National Aeronautics and Space Administration.

Available from the following:

NASA Center for AeroSpace Information (CASI)

7121 Standard Drive

Hanover, MD 21076-1320

(301) 621-0390
National Technical Information Service (NTIS) 5285 Port Royal Road Springfield, VA 22161-2171

(703) $487-4650$ 


\title{
THE AIRCRAFT SIMULATION ROLE IN IMPROVING FLIGHT SAFETY THROUGH CONTROL ROOM TRAINING
}

\author{
Karla S. Shy ${ }^{*}$, Jacob J. Hageman ${ }^{\dagger}$ and Jeanette H. Let \\ NASA Dryden Flight Research Center \\ Edwards, California
}

\begin{abstract}
$\underline{\text { Abstract }}$
NASA Dryden Flight Research Center uses its six-degrees-of-freedom (6-DOF) fixed-base simulations for mission control room training to improve flight safety and operations. This concept is applied to numerous flight projects such as the F-18 High Alpha Research Vehicle (HARV), the F-15 Intelligent Flight Control System (IFCS), the X-38 Actuator Control Test (XACT), and X-43A (Hyper-X). The Dryden 6-DOF simulations are typically used through various stages of a project, from design to ground tests. The roles of these simulations have expanded to support control room training, reinforcing flight safety by building control room staff proficiency. Real-time telemetry, radar, and video data are generated from flight vehicle simulation models. These data are used to drive the control room displays. Nominal static values are used to complete information where appropriate. Audio communication is also an integral part of training sessions. This simulation capability is used to train control room personnel and flight crew for nominal missions and emergency situations. Such training sessions are also opportunities to refine flight cards and control room display pages, exercise emergency procedures, and practice control room setup for the day of flight. This paper describes this technology as it is used in the X-43A and F-15 IFCS and XACT projects.

\footnotetext{
*Simulation Engineer

†Simulation Engineer, Member

$\ddagger$ Simulation Engineer

Copyright $(2002$ by the American Institute of Aeronautics and Astronautics, Inc. No copyright is asserted in the United States under Title 17, U.S. Code. The U.S. Government has a royalty-free license to exercise all rights under the copyright claimed herein for Governmental purposes. All other rights are reserved by the copyright owner.

Notice: The use of trade names or names of manufacturers in this
} document does not constitute an official endorsement of such products or manufacturers, either expressed or implied, by the National Aeronautics and Space Administration.
\end{abstract}

\section{Nomenclature}

\begin{tabular}{|c|c|}
\hline CVT & current value table \\
\hline $\mathrm{DOF}$ & degrees-of-freedom \\
\hline GRIM & Global Real-Time Interactive Map \\
\hline GUI & graphical user interface \\
\hline HARV & High Alpha Research Vehicle \\
\hline IFCS & Intelligent Flight Control System \\
\hline IFPC & $\begin{array}{l}\text { Integrated Flight Propulsion Control } \\
\text { System }\end{array}$ \\
\hline $\mathrm{MCC}$ & Mission Control Center \\
\hline NT & $\begin{array}{l}\text { operating system, Microsoft Corp. } \\
\text { Redmond, Washington }\end{array}$ \\
\hline OTW & out-the-window \\
\hline PAGE & Project Application Graphics Executable \\
\hline PCM & pulse code modulation \\
\hline PDF & Parameter Description File \\
\hline PDS & Parameter Display Software \\
\hline RES & Real-Time Ethernet Server \\
\hline RS 232 & $\begin{array}{l}\text { asynchronous serial data stream, ITU-T } \\
\text { international standard }\end{array}$ \\
\hline SID & simulation interface device \\
\hline TMF & test maneuver feature \\
\hline TRAPS & $\begin{array}{l}\text { Telemetry and Radar Acquisition } \\
\text { Processing System }\end{array}$ \\
\hline UNIX & $\begin{array}{l}\text { operating system, The Open Group, San } \\
\text { Francisco, California }\end{array}$ \\
\hline XACT & X-38 Actuator Control Test \\
\hline VME & Versa Module Eurocard \\
\hline
\end{tabular}




\section{$\underline{\text { Introduction }}$}

Flight safety and mission success are two primary objectives in flight-test programs at NASA Dryden Flight Research Center (Edwards, California). Many processes are exercised through the duration of a flight program to ensure that both objectives are met by all research disciplines and support facilities. The Dryden six-degrees-of-freedom (6-DOF) simulation has long been a valuable tool for achieving mission success. It plays a role during vehicle design and development, ground testing, mission planning, and postflight data analysis. In the last decade, simulation capabilities were expanded to contribute towards flight safety by supporting control room training.

One way to ensure flight safety is to gather the control room staff with the flight crew, connected through audio communication, to simulate a day of flight. With the simulation driving the Mission Control Center (MCC), the control room personnel and flight crew can exercise nominal missions, emergency situations, and communications protocol. Such simulated flight proves especially beneficial for projects with few flights, or projects with new engineers who have little or no previous control room experience. These sessions give both primary and backup personnel the opportunities to develop familiarity with the control room setup, the displays, the flight cards, emergency procedures, and the overall dynamics in the control room on the day of flight. The training also benefits people behind the scenes who are setting up the control room for day-of-flight operations. The MCC support staff can execute many of their control room procedures and evaluate their readiness and efficiency during these training exercises.

These training sessions are also opportunities to improve control room displays. Prior to formal control room training, the simulation can be used to drive the display pages, both statically and dynamically, to check for both aesthetics and function. This can be done either with the displays running in the simulation laboratory, or with the data connection between the simulation and the actual control room. The final test is to use these displays during a day-of-flight training scenario in order to evaluate their effectiveness during an actual mission. Engineers can then verify that the data displayed are pertinent, easy to analyze, and function well with the procedures in the flight cards. Refinements to better suit control room displays to flight objectives, can then be made, contributing to both the safety and success of the mission.
Control room training using flight simulation is also a chance to refine the flight cards for the mission. For a nominal piloted mission, time is critical, emphasizing the necessity for a well thought out, efficient progression through the flight test. During a simulated mission, various sequencing combinations can easily be performed to find the optimum order for maneuvers to maximize the amount of important data gathered while minimizing fuel usage. In the realm of flight safety, the smooth and timely execution of emergency procedures is even more vital. Safety demands emergency procedures be in place for all imaginable off-nominal situations. It also requires that the project procedures work effectively and efficiently as intended. With simulation, failures can be introduced, to test that appropriate and effective emergency procedures are in place.

This paper describes how control room training that uses Dryden simulations is applied in the X-43A (Hyper-X) project and the Intelligent Flight Control System (IFCS) and X-38 Actuator Control Test (XACT) projects. The IFCS and XACT are both flown on the F-15 research aircraft. These programs demonstrate how Dryden consolidates resources between the control room and simulation facilities to provide a valuable capability that meets project objectives. In addition, these efforts reduce both cost and time spent for resource development of tools that can be used center-wide, and expand capabilities of Dryden simulation, from vehicle design to preparation for flight.

\section{Background}

This section discusses the simulation environment and the Mission Control Center, and provides an overview of the capabilities and uses of these facilities. This information broadens understanding and informs readers regarding Hyper-X and F-15 control room training configurations.

\section{$\underline{\text { Simulation Environment }}$}

The Dryden 6-DOF simulation varies in complexity to reflect the requirements of the flight research program. Simulations are designed to be operable by a single user, whether it be a batch version running on a workstation, or a full pilot-in-the-loop configuration. Simulations can also integrate with the actual flight hardware, or software in the hardware-in-the-loop configuration, or both. The fullest use of a simulation is in the aircraft-in-the-loop configuration, where the simulation is integrated with the aircraft itself. 
Each project may require any or all of these levels of simulation complexity. The hardware configurations can be designed specifically for a project, using a dedicated laboratory and simulator cockpit (such as the case for the F-15 simulation), or the project may choose to use a generic glass cockpit and heads-up displays such as in the case for Hyper-X. Regardless of the level of complexity, data monitoring tools are available in the real-time simulation environment, including mechanical strip charts, simulated heads-up graphics, and control room displays, as well as a variety of data analysis software.

The simplest configuration of a typical simulation is the batch mode, also referred to as either an "all software" mode or a "non-real-time" mode. The only hardware required for the batch simulation is a UNIX workstation. The applications for a batch simulation include development and testing of aircraft models, evaluation of aircraft performance, Monte Carlo analysis, and development of new simulation features to facilitate certain applications, if necessary. The batch simulation can also be used to develop procedures for ground tests that use the simulation. The simulation can also serve as a tool to evaluate the test data. Engineers can run a simulation in batch mode at their desk for any of these applications. A graphical user interface (GUI) is provided, allowing easy access to information calculated in the simulation and control of the various functions.

The real-time mode supports configurations that involve a pilot-in-the-loop, hardware-in-the-loop, or aircraft-in-the-loop. The key differences between batch and real-time modes are the addition of a scheduler and the ability to communicate with the desired hardware. In most cases the same program executable is used for both modes, with flags provided at the start determining the desired configuration. Figure 1 shows an illustration of the typical simulation hardware setup.

The pilot-in-the-loop simulation is used to evaluate aircraft performance and stability, test experimental objectives, conduct mission planning and rehearsals, perform overall pilot system assessment, and conduct control room training and checkout of control room displays. This simulation can also be used during the early stages of simulation development, to design the guidance and controls for autonomous vehicles. In the pilot-in-the-loop configuration, the simulation interfaces to a cockpit that uses the Dryden simulation electric stick for pilot inputs and a control panel for push-button control of the simulation.

Visual cues in the pilot-in-the-loop configuration include heads-up graphics and a heads-down instrument panel. The heads-up graphics, projected onto a

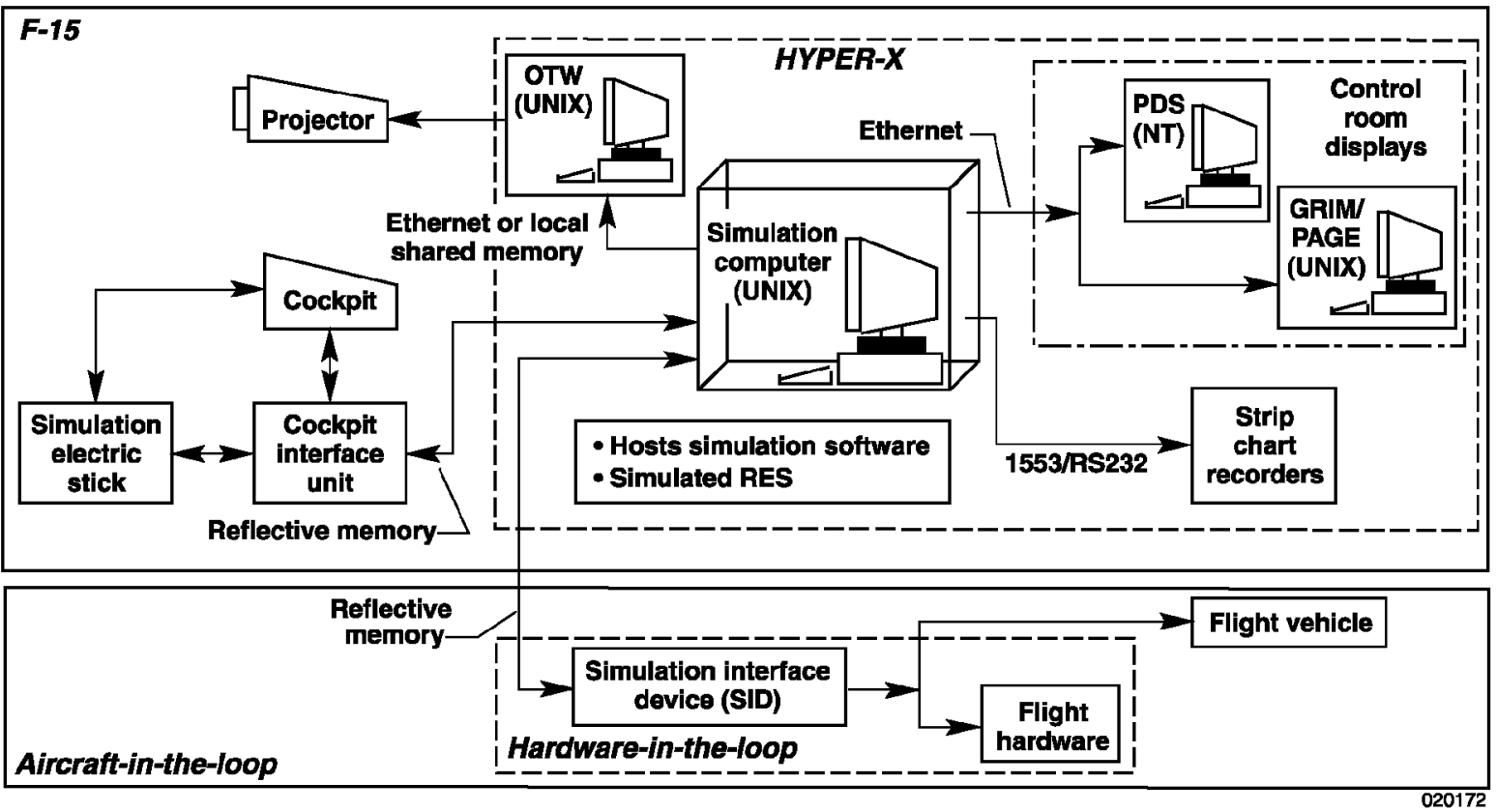

Figure 1. Simulation environment (hardware configuration). ${ }^{1}$ 
2.5-meter diagonal projection screen, includes the terrain, roads, and several base facilities (such as runways, tower, and hangars). The graphics also contain a three-dimensional model of the vehicle with articulated flight controls surfaces and a heads-up display. From the simulation, the user can choose from several viewpoints including an out-the-window (OTW) view, a ground fixed view (such as from the tower or runway), an aircraft fixed view from a chase aircraft, or a view from some other fixed point in space. The cockpit heads-down instrument panel can vary from a full analog replication of the actual aircraft cockpit to a glass-cockpit display with an 8-ball and generic instruments.

Control room displays can also be run in the simulation real-time environment for additional data monitoring capability, either in the laboratory environment or during ground tests. Engineers can use this environment to design and evaluate the effectiveness and functionality of control room displays. This environment also gives the users an additional opportunity to familiarize themselves with these displays in preparation for the day of flight.

Strip charts, driven by simulation data, allow the engineers to monitor data and evaluate various data configurations for use in the control room. In the case of the F-15 simulation laboratory, the same model of strip charts are used as in the control room, allowing users to save the desired configuration to a disk for use at either location.
The hardware-in-the-loop simulation configuration supports (1) functional checks for both flight hardware and flight software; (2) closed-loop performance; and (3) preparations for aircraft-in-the-loop testing. In this configuration, the simulation interfaces with actual flight hardware or software. The simulation can monitor data output from these elements and provide inputs to drive these flight articles. The controlled environment provided by the simulation is often used for failure modes and effects testing and validation of new hardware before it is installed in the aircraft. In the aircraft-in-the-loop configuration, the simulation interfaces to the vehicle in a similar manner to support full mission, integrated closed-loop testing.

All Dryden simulations use the same basic software skeleton (fig 2). ${ }^{2}$ The aircraft models vary in each simulation to reflect the corresponding research vehicle. The basic models include the flight control system, actuator model, aerodynamics model, and engine model. In the real-time configurations, the simulation has routines to interpret inputs from the simulation cockpit or flight hardware. Outputs from the simulation are also sent to drive cockpit instruments and displays, and flight hardware and software. Simulations features typically include the ability to produce linear models, automated maneuvers, data recording and use of scripts, as well as many project-specific tools.

\section{$\underline{\text { Mission Control Center (MCC) }}$}

A Mission Control Center (MCC) is composed of a control room, and Telemetry and Radar Acquisition Processing System (TRAPS) facility with input from

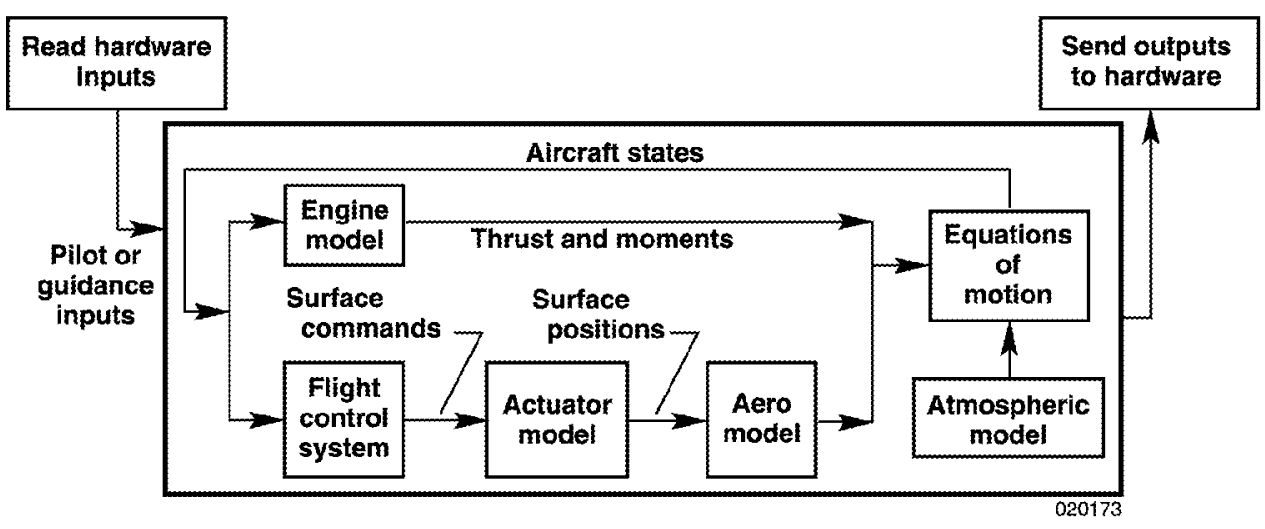

Figure 2. Simulation software structure. 
pulse code modulation (PCM), radar, and video streams, as shown in figure 3 .

The control room includes numerous flight test engineer and research stations supporting many different functions such as range safety and control, mission control, flight operations, and research. The control room is configured with overhead video monitors, communication panels, strip chart recorders, weather and timing displays, and graphics workstations.

Video monitors are used for the display of aircraft downlink and tracking video. Fixed and mobile camera systems acquire operational video data for monitoring, control, and safety purposes. Communication panels are available at every workstation in the control room, providing voice links between the TRAPS area, the control room, the simulation laboratory, and the research aircraft. Graphics workstations are available throughout the control room, while strip chart recorders are located at the research stations only.

The TRAPS processes data for the control room and is composed of several front-end computers, a data server, and data recorders. The TRAPS performs the data processing and delivery service for the control room. The system can process multiple PCM streams supporting data rates up to $20 \mathrm{Mbits} / \mathrm{sec}$, providing the capacity of a maximum of 64,000 downlink parameters for display in the control room. The front-end computers are responsible for data processing of the telemetry and radar streams. This processing includes decommutation of the PCM streams and conversion of PCM data from telemetry count values to engineering units. The front-end computers are also responsible for parameter derivations, data storage in reflective memory, at-rate data delivery to the strip charts, and data archiving for postflight analysis. The Real-time Ethernet Server (RES) gathers the data from the reflective memory and distributes it to the control room through Ethernet. The raw PCM and radar data, as well as time-stamps are stored on the data recorders in the TRAPS.

Two types of data are available in the control room: at-rate and RES. At-rate data consists of the downlink parameters only and is supplied to the strip chart recorders. The RES provides a current value table (CVT) to the graphics workstations in the control room for special purpose displays. The CVT contains all parameters; PCM, radar, system, and derived-at a given instance in time.

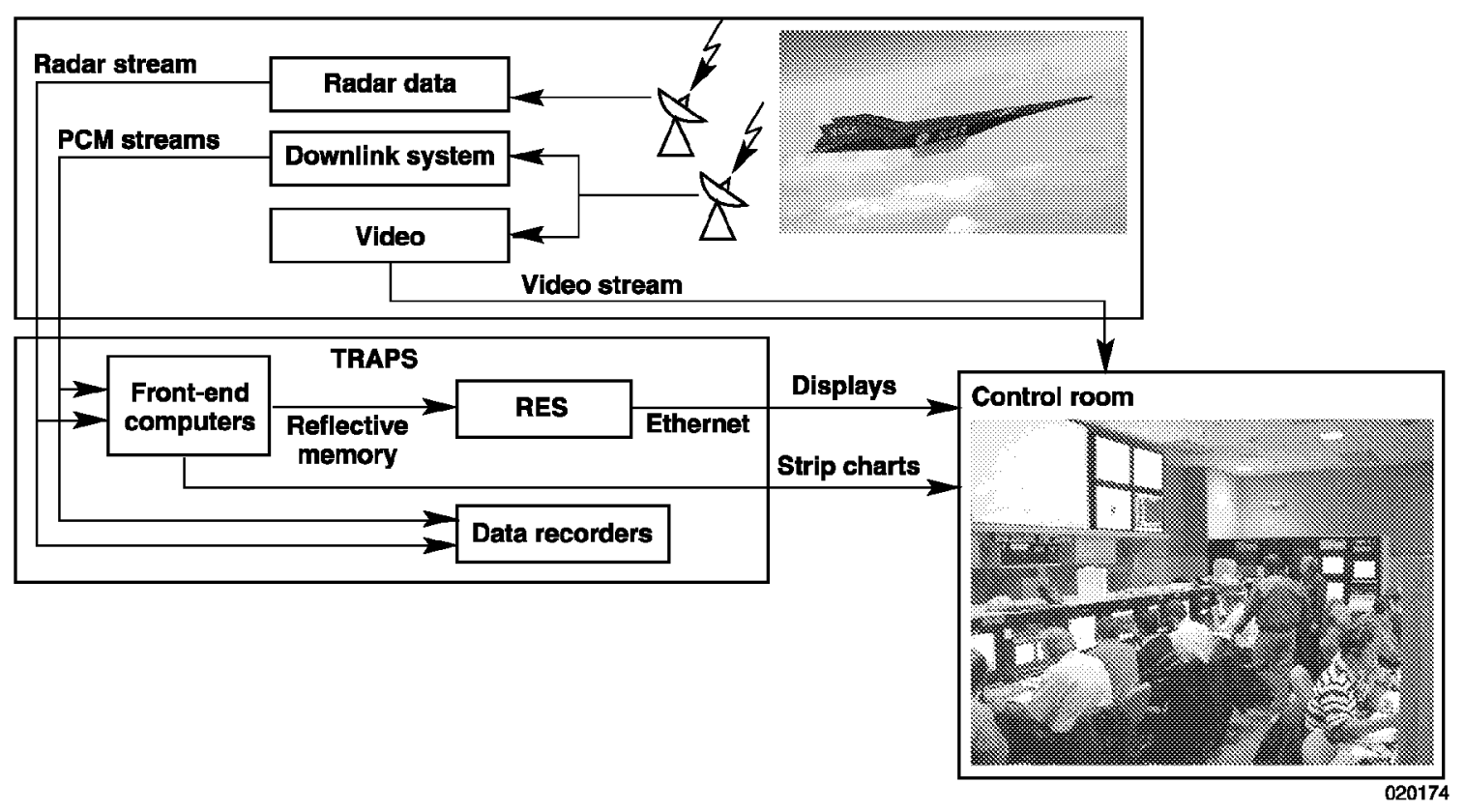

Figure 3. Mission Control Room configuration. 
The special purpose displays consist of the Global Real-Time Interactive Map (GRIM), Parameter Display Software (PDS), and Project Application Graphics Executable (PAGE). The GRIM application (fig 4) allows range safety personnel the ability to track multiple targets anywhere in the world by providing a graphical representation of vehicle position on a simplified map with range information. The PDS application (fig 5) is a re-configurable display tool, with features such as alphanumeric displays, light panels, bar graphs, and discrete messages. Where limitations in PDS occur, the PAGE application (fig 6) can be used to provide custom graphical displays. The page application is most commonly used to display vehicle stick, rudder, and control surface positions. Logic can be built into these displays for fault-error detection, either through the derivations in the front-end or through the applications themselves.

\section{Control Room Training Configurations}

Several current projects demonstrate how the simulation drives the MCC to support control room training, such as the X-43A (Hyper-X) and two F-15 (IFCS, XACT) projects. These projects were selected to demonstrate the different configurations for which the simulation environment can be adapted. For each project, this section will outline how the simulation facility interfaces with the control room and how information is generated to drive the mission control room facilities, simulating day-of-flight operations.

\section{Hyper-X Training Configurations}

Control room training is accomplished on the Hyper-X project using the simulation in two ways. The first method is to combine training with a ground test that uses the simulation in the aircraft-in-the-loop configuration, shown in Figure 7. The data is typically transmitted to the control room through the downlink system for data recording and provides an opportunity for additional control room display checkout. The test can be conducted from the vehicle location or the control room, allowing engineers the ability to walk through various parts of a simulated mission and gain control room familiarization.

The more common configuration used on Hyper-X has the real-time simulation residing on a UNIX workstation installed in the TRAPS facility (fig 8). A direct connection from the control room to the simulation lab is not required, since the Hyper-X project involves an autonomous vehicle and no pilot-in-the-loop capability is needed. All one needs is a simulation computer that broadcasts data to whomever wants to listen, in this case the control room.

The control room displays get their data through an Ethernet broadcast from the RES. Since the Hyper-X

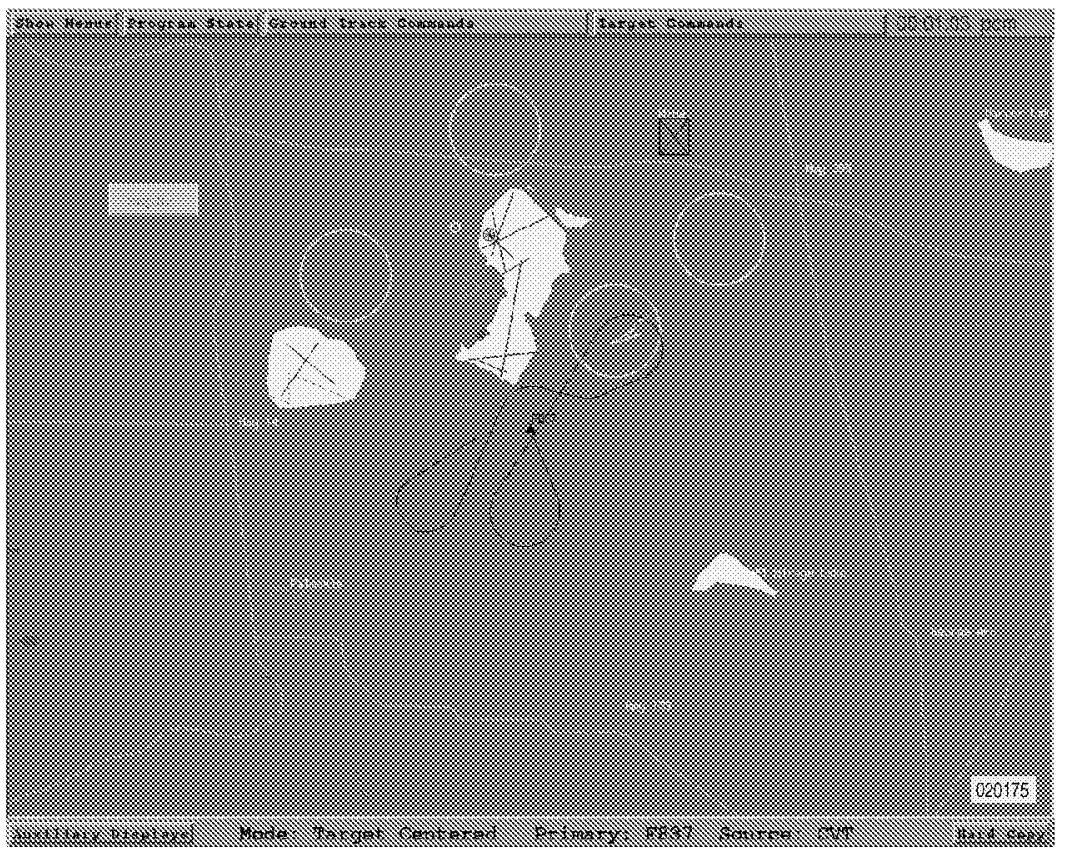

Figure 4. F-15 Global Real-Time Interactive Map (GRIM) example. 


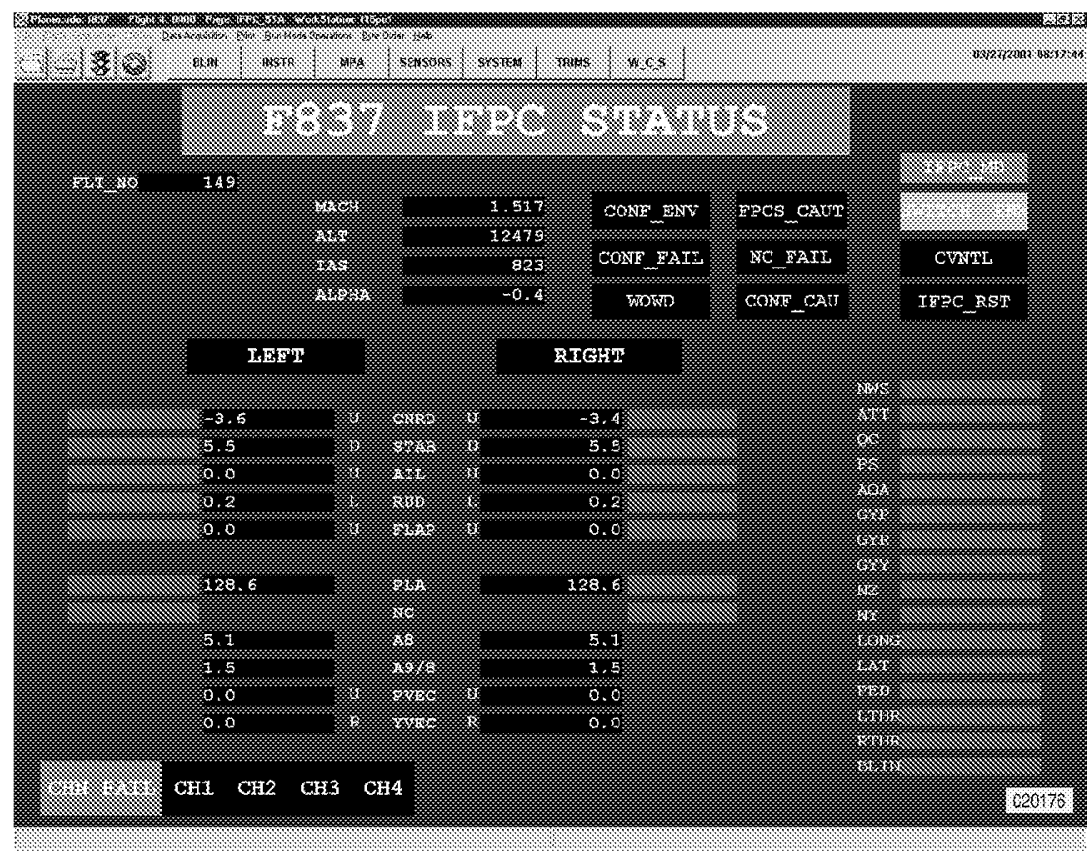

Figure 5. F-15 Parameter Display Software (PDS) example.

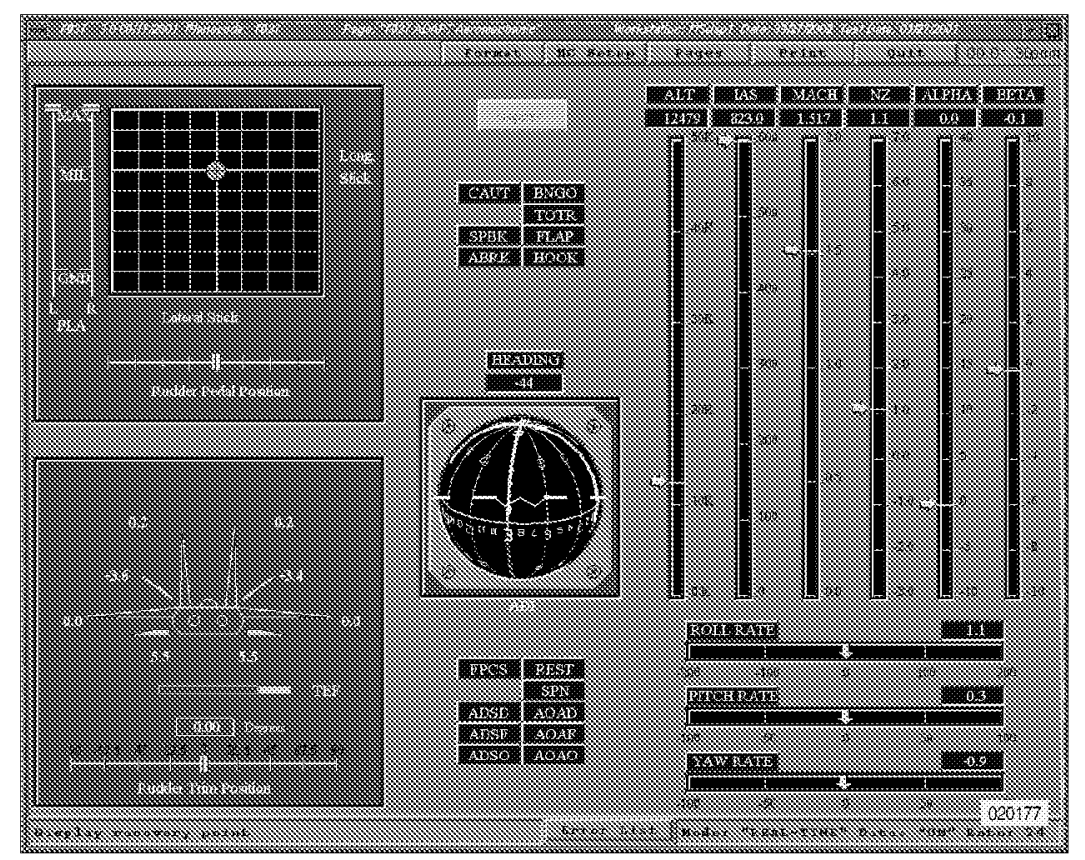

Figure 6. F-15 Project Application Graphics Executable (PAGE) example. 


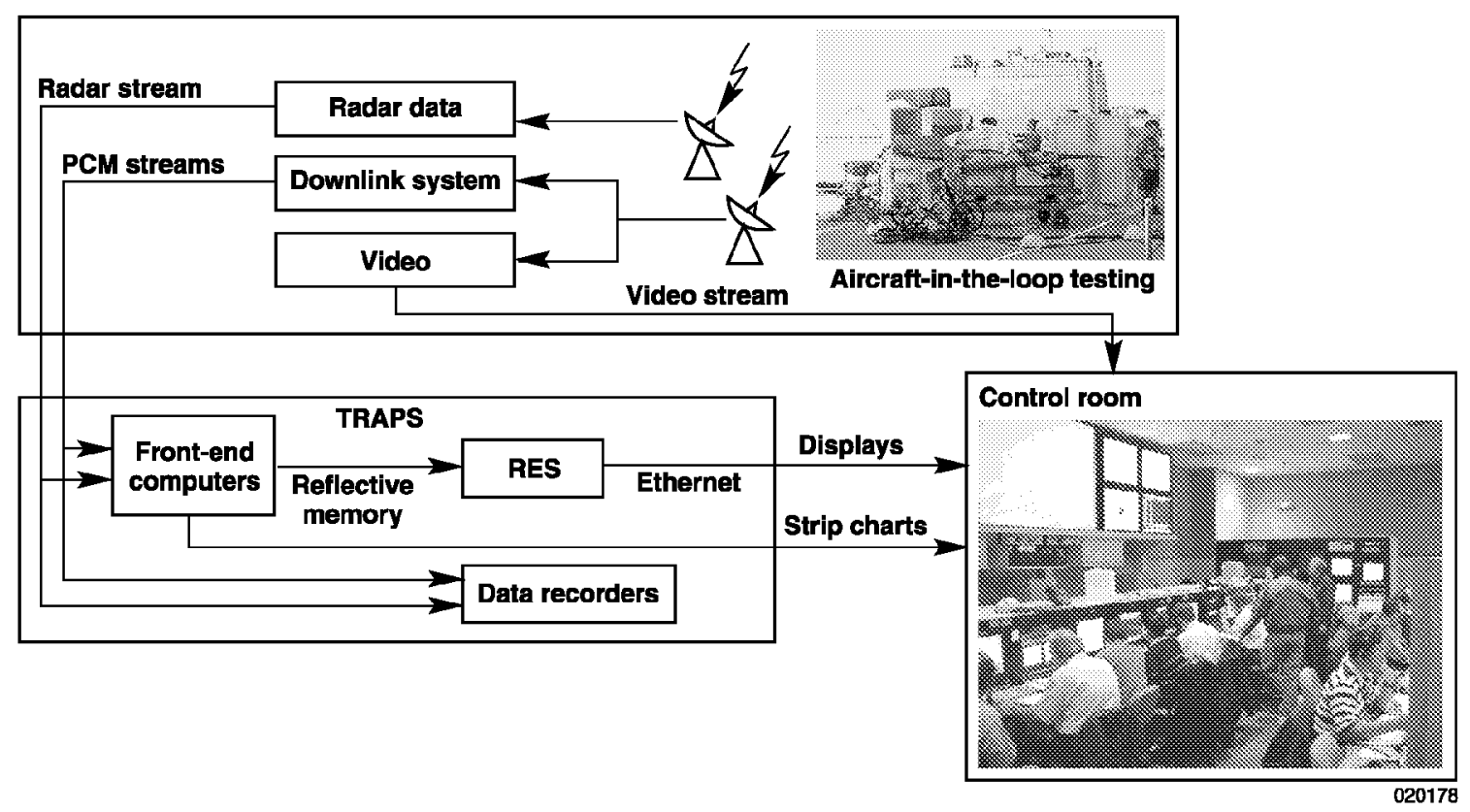

Figure 7. Hyper-X ground test using the simulation in the aircraft-in-the-loop configuration.

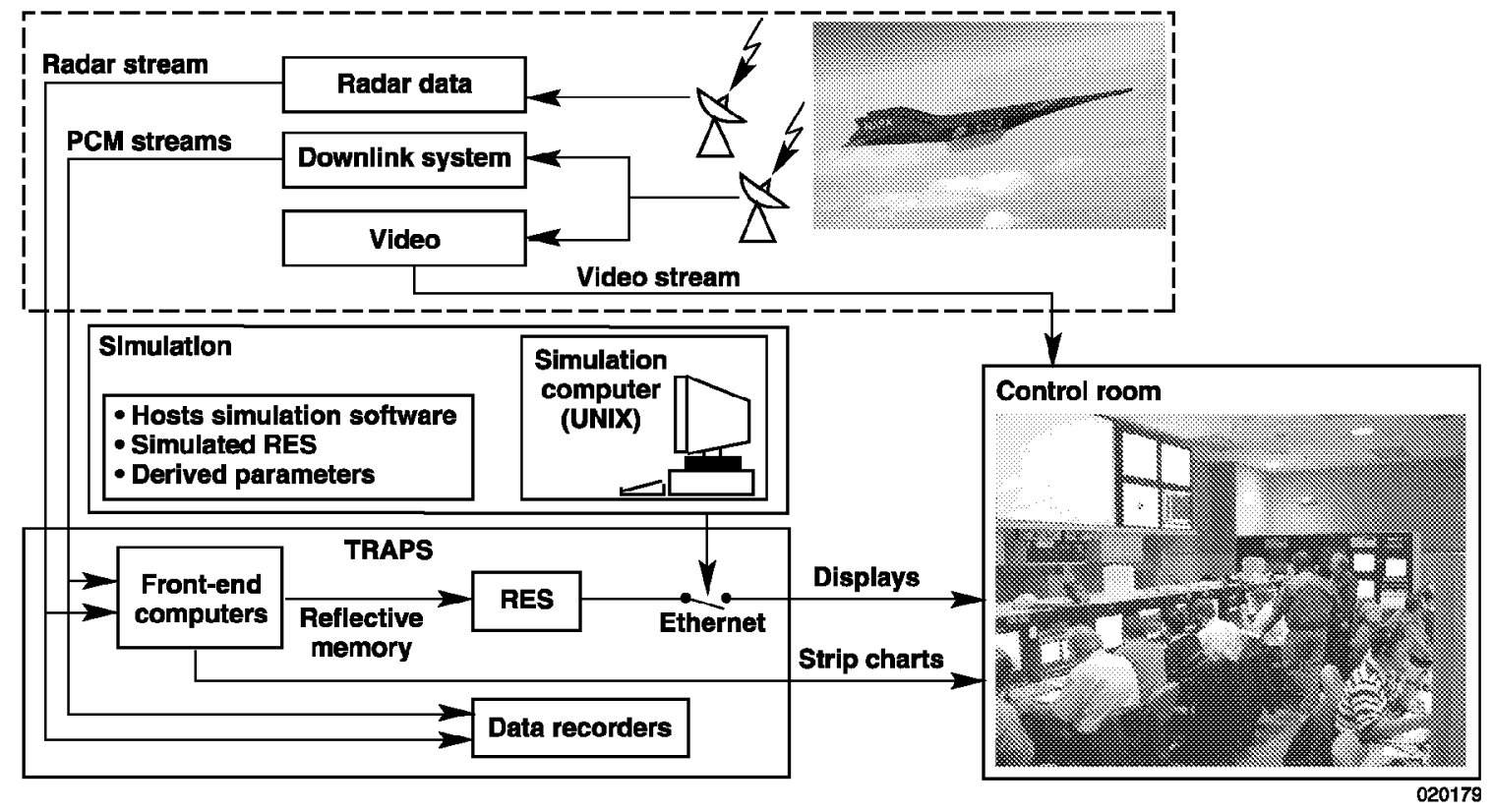

Figure 8. Hyper-X control room training configuration using real-time simulation to simulate flight data and the Real-Time Ethernet Server function. 
simulation already includes the ability to mimic RES, it is used as the interface to the control room, driving everything downstream of this junction. The software used by the control room to compute the derived parameters is also run in this simulation since many of these parameters appear on the displays.

\section{$\underline{\text { Simulated Real-Time Ethernet Server }}$}

The simulated RES function does basically two things: maps simulation parameters to the CVT, and sends the CVT data to the applications that need it. First, it creates and writes a CVT using the simulation data with the aid of two input files. The initial file is the CVT itself that is provided by the MCC. Both the simulation and the MCC must use the same CVT file or the parameter mapping will be incorrect. Second is a parameter description file (PDF) that may contain all, or just a subset of, the CVT parameters. It also contains the associated simulation parameter name that will be used to drive that CVT parameter. The parameters in the PDF file are PCM, radar, system, and derived parameters. Once the simulated RES has built the CVT, the data is broadcast on Ethernet. The CVT data then becomes available to the graphics workstations in the control room.

The software that simulates the RES runs as a separate process, either synchronously or asynchronously with the simulation. This process is started by the simulation software and can also be stopped and restarted at any time through the simulation GUI. The user then has the ability to update the input files for the data mapping and restart RES without bringing down the entire simulation. For the Hyper-X project the RES process was synchronized with the simulation.

\section{Hyper-X Training Objectives and Scenarios}

The primary objectives of the control room training sessions for the Hyper-X project are to prepare the control room staff for nominal and off-nominal missions, improve the quality of the flight cards, and optimize the effectiveness of the control room displays.

Building control room proficiency improves flight safety and mission success. The opportunities to walk through a day-of-flight training scenario are critical for projects like Hyper-X, where there are few missions and large time gaps between flights. These also prove to be beneficial for personnel who have little to no experience being in the control room to support a flight.

The project also used control room training sessions to improve the quality of flight cards and emergency procedures. These training sessions ensure that procedures are in place for all anticipated scenarios and that they function correctly. Engineers check to see that procedures are sequenced properly and serve their intended purpose. They also check that the control room displays allow them to make their decisions in a correct and timely manner.

For Hyper-X, there were a total of three nominal training sessions and three emergency procedures training sessions within a five-month period before first flight. The flight scenario usually begins at or before taxi and continues until the end of the flight experiment or splashdown. Figure 9 shows the Hyper-X flight profile. During all sessions, the control room is fully staffed

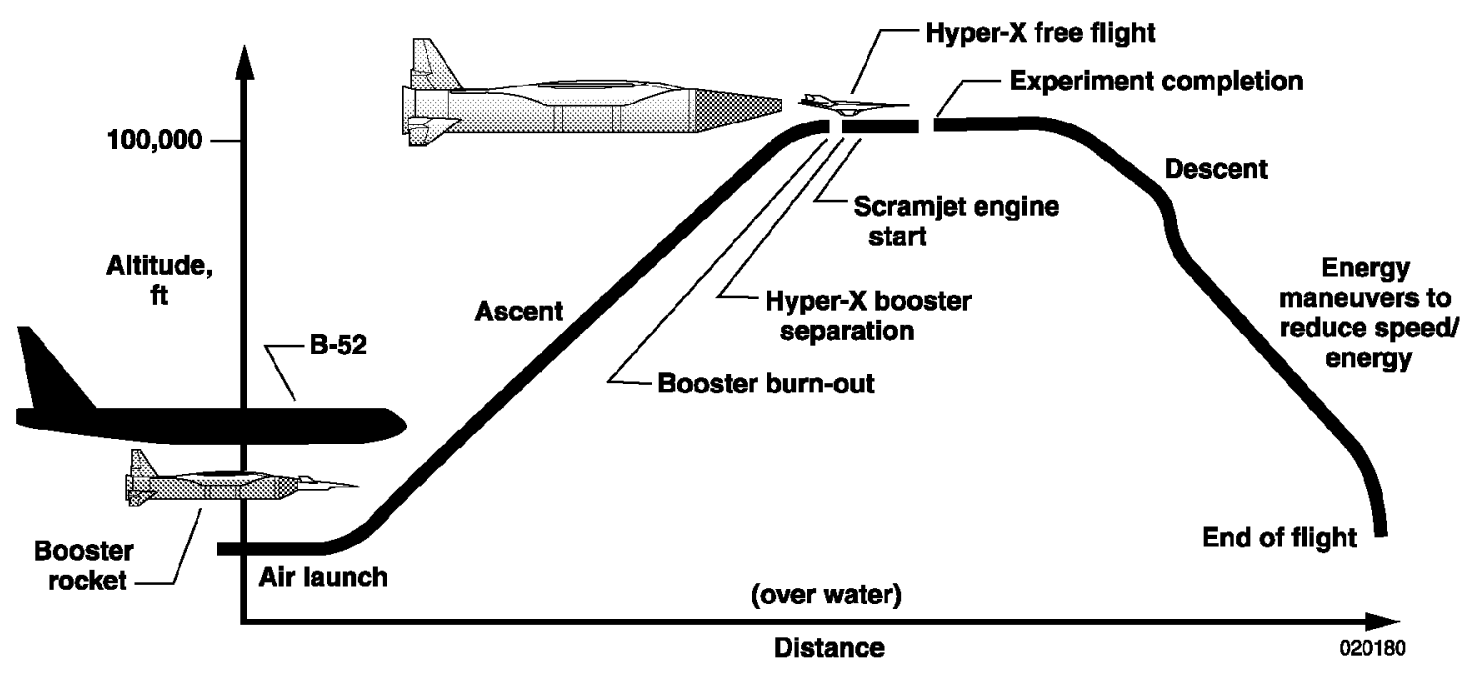

Figure 9. Hyper-X flight profile. 
with either primary or back-up personnel. The B-52 flight crew is also present on audio communication to perform duties specified by the flight cards.

For each session, engineers have access to all available control room displays designed for the project; mechanical strip charts; and the GRIM display showing the ground track for the B-52, launch vehicle, and research vehicle. The simulation provides all data required to drive the control room displays during the mission, which is usually a subset of the entire downlink parameter set. For Hyper-X, approximately 25 percent of the CVT data (or close to 1200 parameters) were driven for the training sessions, either statically or dynamically.

Communication in the control room during the day of flight is also a critical element factored into these training sessions. Various audio communication lines are set up to reflect the day of flight. One line connects the test conductor, flight crew, and the mission lead. Another communication line allows all the discipline leads to communicate with each other. Then a separate line is available to allow members of each discipline to talk amongst themselves. For these training sessions, an isolated line is also set up between the simulation engineer (sitting in the TRAPS area) and the safety representative (in the control room) who calls to the simulation engineer to initiate the various scenarios. During emergency procedures training, only these two individuals know what the off-nominal scenarios are in order to maintain the element of surprise for the remaining control room staff.

For off-nominal training scenarios, the simulation can inject a failure on any control room parameter driven by the simulation, to provide opportunities to exercise go-no-go criteria and emergency procedures. Engineers who need to make these calls have to rely on the display page information to make their decisions correctly and in the time allowed. Thus, the emergency training also helps them design the displays to provide them with the data they need, when they need it. If an abort is called, the simulation can take the project through that sequence and end the training session. Alternatively, the reactions to the failure are noted, then the simulation returns to a nominal state and the training proceeds to the next scenario. Failures may not be modeled exactly, but the first-order effects are included for training purposes.

As in the day of flight, there is a briefing before each training session, but more importantly there is a debrief immediately afterwards to evaluate the training. In the debrief, the project reviews the results of the training, the quality of the flight cards, how well people communicated in the control room, the quality of the control room displays, the setup and station assignments, and any other issues that came up during the training. Feedback from people is also used to help formulate or improve future training sessions.

\section{$\underline{\text { Hyper-X Training Data Manipulation }}$}

Figure 10 shows data can be manipulated in several ways. The simulation has a feature called "Autotest" that allows the user to force a profile on a desired parameter. The user can superimpose steps, square waves, doublets, ramps, sine waves, or frequency sweeps to create the desired parameter profile. The user specifies the parameter name, location in the real-time loop where this profile is injected, and characteristics about the profile, such as times, amplitudes, and frequencies. Up to 512 parameters with four test legs per parameter can be manipulated through this feature.

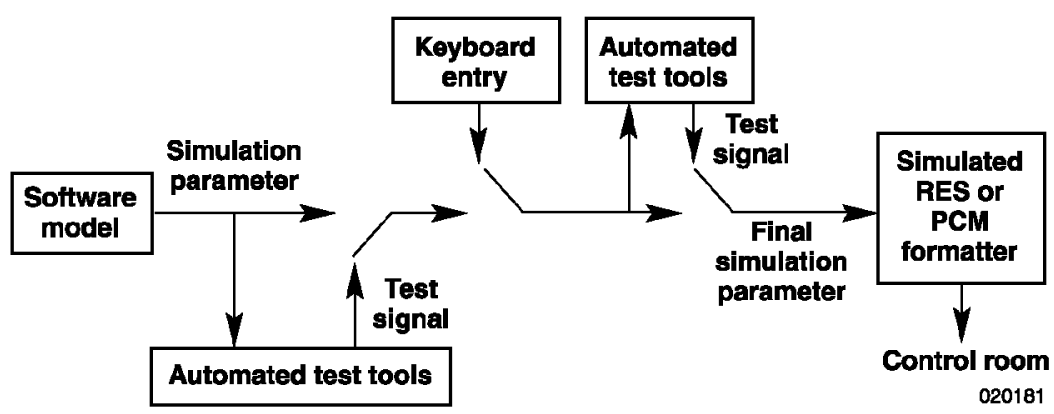

Figure 10. Simulation data manipulation to drive control room displays. 
Another method of manipulation is the Test Maneuver Feature (TMF) that uses an input file containing a specified time history profile of a desired parameter. For each parameter, the user provides a time array and a data array and the location in the real-time loop. The user can specify whether to add this time history profile on top of the existing data value produced by the simulation models or equations of motion; or replace the value entirely by the time history profile. Each profile is read in during simulation initialization, and can be turned on or off at any time from a simulation display page and command line.

Data produced by both the Autotest and TMF are entirely time-based. In other words, the user pre-determines when a test profile is applied to a parameter, especially on parameters that are produced from simulation models and must be overridden to produce an off-nominal condition. For example, the square wave of the Autotest feature was used to introduce an intermittent failure on certain parameters during emergency procedure training. Similarly, the TMF was used to generate the ground-track for the mission from taxi to launch, overriding the outputs of the equations of motion. The data values can also be changed from the simulation command line to set a new value for a desired parameter. This can be done at any time, as the safety representative makes the call from the control room.

The simulation can imitate a telemetry data loss with the ability to stop and restart RES from the simulation GUI command line. Though it doesn't truly depict a telemetry loss that normally results in data being frozen at randomly large numbers, the simulated telemetry loss holds the data at last-value until RES is restarted.

Generally, for all these training sessions, simulation scripts are used to ensure repeatability and easy updates for other training sessions. The scripts are just lists of commands that the user would normally type from the simulation command line along with comment statements. Scripts are run to initialize all the parameters on the control room displays and to introduce various failure scenarios. Scripts can also be nested within others, making it easy to re-use scripts from other sessions if applicable.

Since the simulation has a feature that allows the user to freeze the simulation, the training session can be temporarily halted at any time if a discussion amongst the control room staff is needed before moving on. When ready, the simulation can resume the test where it was left off.

\section{F-15 Training Configuration}

Unlike the Hyper-X program, the F-15 project requires a pilot-in-the-loop, making the simulation laboratory cockpit an essential part of the control room training configuration. While the F-15 simulation does use simulated RES to drive control room displays, it does so only when these displays are used in the laboratory environment. To communicate with the MCC, flight data is instead generated by the simulation as raw PCM, radar, and video streams. The PCM and radar streams are sent to the TRAPS facility through fiber connections for decommutation and processing, with the resulting data being sent to the control room. The heads-up graphics produced by the simulation are also sent to the control room to simulate aircraft downlink or tracking video through a fiber connection. Audio communication is set up to allow the control room personnel to talk to the pilot as if on day-of-flight, with a separate communication line for the simulation engineer used in a manner similar to the Hyper-X program. A graphical representation of the configuration is shown in figure 11.

The F-15 configuration is more complex than that of Hyper-X, and it exercises more of the MCC systems, allowing a more complete test of the associated hardware and software. Additional hardware and software is required in the simulation laboratory to create the required data streams, but once these streams reach the control room they appear exactly as if they were coming from the aircraft. This configuration allows for a complete end-to-end check of the MCC systems including all of the TRAPS.

\section{$\underline{\text { Simulated PCM, Radar, and Video }}$}

For the F-15 IFCS and XACT projects control room training, the PCM, radar, and video streams must be generated in the simulation laboratory using data produced by the simulation and PCM processing packages, as shown in figure 12 .

The PCM processing package is composed of two applications, the PCM Server and the PCM Formatter. The PCM Server is generated as a separate process from the F-15 simulation. The PCM Server determines which simulation parameters are required for the PCM streams, converts the simulation values to telemetry count values, and stores the resulting values in reflective memory. The "pcm_process" file is used by the PCM Server to indicate which simulation parameters are to be mapped to which PCM parameters, and contains the necessary information to convert the engineering units

11 


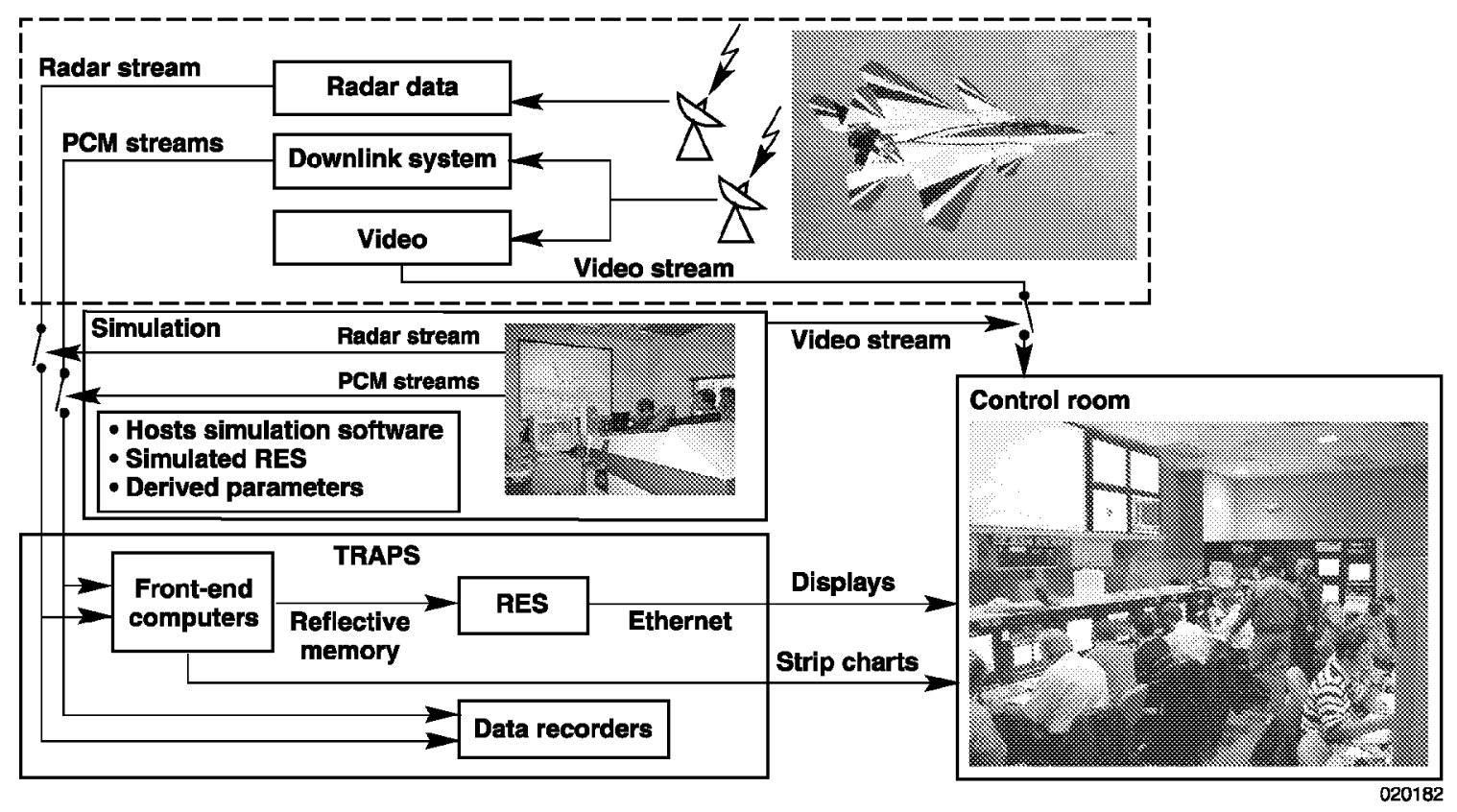

Figure 11. F-15 IFCS and X-ACT control room training configuration using the F-15 simulation.

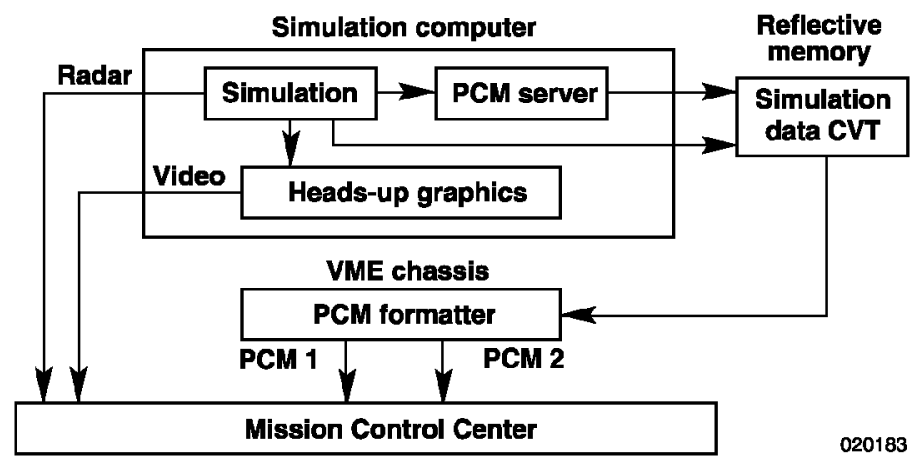

Figure 12. F-15 methodology for simulating PCM, radar, and video data streams for the MCC. 
of the simulation values to telemetry count values. ${ }^{3}$ The PCM Formatter builds the two required PCM streams for the F-15 projects on a system located in a versa module eurocard (VME) chassis using the telemetry count values in the reflective memory. The "pcm vme" file is used by the PCM Formatter to identify which parameters are needed, where to find them in reflective memory and how to build the PCM streams. Once the PCM streams are built they are transmitted on fiber connections, one line for each system, to the MCC. When the PCM streams reach the TRAPS they appear exactly as if they were coming from the aircraft and are processed accordingly.

The radar stream is generated in the F-15 simulation based on positional information that is converted into a raw radar format. The raw radar stream leaves the F-15 simulation computer on an RS-232 connection that is converted to fiber and then proceeds to the MCC where it enters the TRAPS for processing.

The heads-up graphics are used to simulate video for the control room. A scan converter is required in the F-15 simulation laboratory to transmit the graphics for display in the control room. The video stream is sent over a fiber connection, directly to the control room for display on the overhead video monitors.

\section{F-15 Training Objectives}

The objectives of the control room training sessions for the F-15 IFCS and XACT projects, like the Hyper-X project, are to prepare the control room staff for nominal and off-nominal missions, improve the quality of the flight cards, test various communication protocols, and optimize the effectiveness of control room displays.

Building control room proficiency contributes greatly to improving flight safety and mission success. The F-15 IFCS and XACT projects used these sessions for training primary and backup project personnel. The project personnel ranged from new inexperienced engineers who required more extensive training, experienced engineers who needed refresher training, to engineers covering new responsibilities who required more specialized training. As an additional benefit, new project pilots were given the chance to interact in the simulation environment with both primary and backup project personnel, and at the same time become more familiar with the upcoming missions.

As in the Hyper-X project, the control room training sessions were used to improve the quality of the flight cards and emergency procedures. Fuel use and coordination with other aircraft and range activities require the flight to be efficiently planned out from before takeoff to after landing. Executing these missions in the simulation environment allow personnel to prioritize and rearrange test maneuvers to acquire the maximum amount of useful data within the allowed flights. In emergency situations, there are many procedures involved in attempting to regain control of the system, such as system resets or activation of emergency systems. The coordination of activities is of utmost importance in such a high-stress situation, and through practice, personnel can better learn their roles and responsibilities.

Communication in the control room during day-of-flight is a critical element factored into these training sessions. During the real mission, too little or too much communication can be disastrous. Adding to the complexity, the F-15 aircraft has two simultaneous experiments being flown. Since F-15 was training a new test conductor, multiple communication configurations were tested in search of one ideal to the missions. In the final configuration, three communication paths were set up for the project personnel, with one additional path used for simulation control information to be shared among the people running the session. The first line included the pilot, test conductor, simulated tower and traffic, and the lead for each of the two experiments. The second line was for the discipline leads to communicate with each other, as well as with the experiment leads. A third communication line was set up for internal discipline conversations. The line used for simulation control included the simulation engineer, a veteran pilot, the test information engineer, and a safety representative. The veteran pilot and safety representative notify the simulation engineer when to inject errors, and the test information engineer and simulation engineer verify that all the required equipment is working correctly.

The control room displays and strip charts show all important aircraft and experimental information to the control room personnel. This information gives a complete view of the aircraft, allowing the engineers to control the flight test and ensure safety. Some of the critical parameters are not available in the cockpit for the pilot, requiring the responsible engineer to interpret the display or strip chart and communicate the results to the proper people. As an objective of the training, the control room personnel evaluate their displays and strip charts to verify reception of all required information in a clear, timely manner. Corrections and modifications are made and then tested, with this cycle repeating until requirements are met. 


\section{F-15 Training Scenarios}

For the F-15 projects, many training sessions were conducted within a nine-month period before the first flight. The flight scenario usually begins at or before taxi, then continues until landing for the majority of missions, or loss of aircraft in extreme emergency situations. During all sessions, the control room is fully staffed with either primary or backup personnel, and the simulation laboratory is staffed with the pilot in the cockpit and a simulation engineer monitoring and controlling the required hardware and software. The hardware and software include the simulated cockpit systems, related flight hardware, video converter and switches, and PCM processing equipment, as well as the standard simulation software and simulation computer.

Before any simulated flight began, a flight brief was conducted in the same ways as for a real flight. Weather and range conditions were covered and no-go parameters were reiterated and assigned to the appropriate control room personnel. This is also when flight cards are given the final review, and any special responsibilities are assigned.

During each session, the engineers have access to all available control room displays designed for the project, mechanical strip charts, and the GRIM display showing the ground track of the research vehicle. The simulation provides all the data required to drive the control room displays during the mission, which is usually a subset of the entire downlink parameter set. For the F-15 projects, over 900 parameters were driven for the training sessions, either statically or dynamically. The simulated video (fig 13 and 14) is available for display on the overhead monitors in the control room, with the ability to simulate the pilot's view, chase aircraft view, and various fixed views.

Unlike the Hyper-X, the F-15 training scenarios were very dynamic in nature. The first sessions approximated a nominal mission, with the injected errors corrected or worked around and flights continued successfully to completion. This was done to allow the control room personnel a chance to become accustomed to the environment, and evaluate their displays for nominal operation. The third session began the emergency training, where the observing veteran pilot and safety representative evaluated the rest of the project team. On the private communication line, either the veteran pilot or safety representative requested the initiation of an error. Once an emergency procedure started, the veteran pilot or safety representative could call for more errors to be injected or allow the procedures to correct the problem. In one of the later scenarios, the errors were allowed to compound until ejection of the pilot was

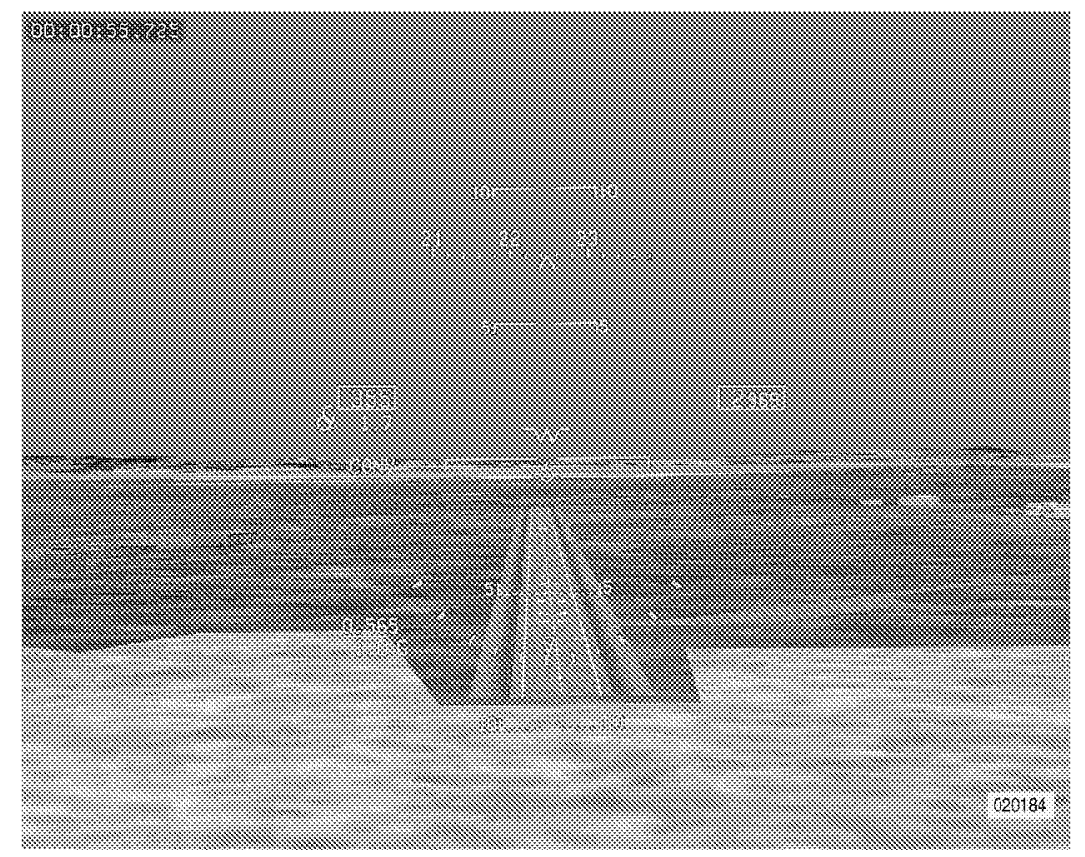

Figure 13. F-15 heads-up out-the-window graphics. 


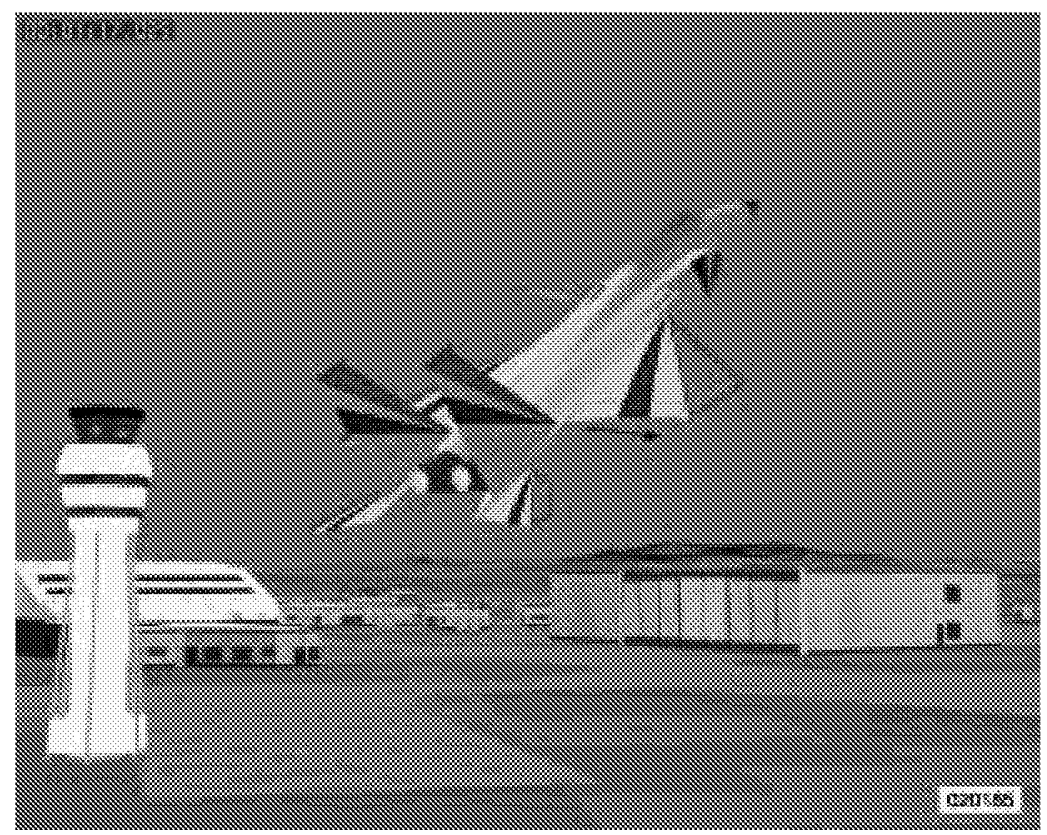

Figure 14. F-15 simulated video.

required, ending the mission. In this way, the team as a whole had a wide range of experiences, from a good flight to a very high-stress, difficult mission ending with loss of the aircraft.

A debrief was conducted after each training session, covering all the significant portions of the flight. The veteran pilot and safety representative assessed the performance of pilot and crew, making suggestions for future training. This also gave a chance for the project personnel to suggest changes to displays, procedures, and flight cards.

\section{$\underline{\text { F-15 Training Data Manipulation }}$}

For the F-15 project, there are many failures of varying likelihood that could occur, ranging from total data loss to a nuisance error on an experiment. In the training sessions a set of anomalies are chosen representing some of the more common problems as well as scenarios requiring in-depth knowledge of the emergency procedures. Some events were thrown in as simple annoyances, for such uncontrollable occurrences can add to the stress level in the control room environment. The four categories of problems involve the environment, pilot or communications (or both), the experiment, and basic aircraft systems.
The environmental problems are simulated using tower and traffic communications. The safety representative performed tower communication, and an experienced person from outside the project simulated the traffic communication. Delays were simulated on the ground by wind conditions exceeding the no-go limit for the aircraft and objects on the runway. Once in the air, traffic was noted and adjusted for, and cloud conditions caused changes in flight plans. On landings, different runways were utilized to avoid hazards, or in case of emergency landings to avoid creating hazards for other aircraft.

Communication and pilot errors were also injected at inconvenient times in the flights. Simulated loss of communication with the pilot was done by simply not allowing the pilot to talk over the headsets, requiring interaction with the chase aircraft. Skipping flight cards and incorrectly performing maneuvers simulated pilot error. There was even a point where the pilot requested an unauthorized refueling.

Experimental and basic aircraft systems failures were done both with the simulation software, and by simply announcing an error had occurred. From the simulation, flight control failures can be induced on a single channel of a subsystem, multiple channels of a subsystem, complete channel failures for the entire system, or any 
combination of the above. This allows for any assortment of failures for systems, such as air data measurements, surface controllers, nosewheel steering, gyro sensors, and accelerometers. For each type of error, there is a specific emergency procedure to follow, often including resetting the system, using alternate systems, or immediate return to base. A random set of these flight control failures were injected during the training sessions, both individually and in conjunction with other failures. Simulated engine failures were conducted by simply not allowing the pilot to use the throttles, or announcing an anomaly, such as that an engine fire occurred. In the case of the engine fire, the emergency procedures were ineffective, forcing the project team to proceed to a pilot ejection.

\section{Concluding Remarks}

Good mission preparation is key to both flight safety and mission success. As demonstrated in the X-43A and F-15 projects, the Dryden simulation is an existing design and analysis tool that can also support control room training to help achieve these objectives in an efficient, cost-effective manner. The training sessions not only prepare the control room staff for the day of flight, but they also allow for improvements in control room setup and displays, flight cards, and emergency procedures. Also, by taking advantage of existing technologies and resources, the training configurations require less cost and time to develop, while greatly expanding the capabilities of the Center.

The project manager for F-15 described this ability as an "excellent training opportunity and extremely useful for the project team". For the autonomous X-43A project, the project chief engineer found that "through these near-realistic practices, we were able to effectively (train) primary personnel and backups, ... ended up with highly effective control room displays, ... (and) developed a high level of confidence and preparedness."

\section{$\underline{\text { References }}$}

${ }^{1}$ MIL-STD 1553B, Military Standard, Aircraft Internal Time Division, Command/Response Multiplex Data Bus, Department of Defense, January 1996.

${ }^{2}$ Norlin, Ken, Flight Simulation Software at NASA Dryden Flight Research Center, NASA TM-104315, October 1995.

${ }^{3}$ Fantini, Jay, Conversion From Engineering Units to Telemetry Counts on Dryden Flight Simulators, NASA CR-1998-206563, October, 1998. 
Public reporting burden for this collection of information is estimated to average 1 hour per response, including the time for reviewing instructions, searching existing data sources, gathering and maintaining the data needed, and completing and reviewing the collection of information. Send comments regarding this burden estimate or any other aspect of this collection of information, including suggestions for reducing this burden, to Washington Headquarters Services, Directorate for Information Operations and Reports, 1215 Jefferson Davis Highway, Suite 1204 , Arlington, VA 22202-4302, and to the Office of Management and Budget, Paperwork Reduction Project (0704-0188), Washington, DC 20503.

\begin{tabular}{|l|l|l|}
\hline 1. AGENCY USE ONLY (Leave blank) & $\begin{array}{l}\text { 2. REPORT DATE } \\
\text { August } 2002\end{array}$ & $\begin{array}{l}\text { 3. REPORT TYPE AND DATES COVERED } \\
\text { Technical Memorandum }\end{array}$ \\
\hline
\end{tabular}

4. TITLE AND SUBTITLE 5. FUNDING NUMBERS

The Aircraft Simulation Role in Improving Flight Safety Through Control

Room Training

6. AUTHOR(S)

$7065154 \mathrm{~T} 45600 \times 43$

Karla S. Shy, Jacob J. Hageman, and Jeanette H. Le

7. PERFORMING ORGANIZATION NAME(S) AND ADDRESS(ES)

8. PERFORMING ORGANIZATION

REPORT NUMBER

NASA Dryden Flight Research Center

P.O. Box 273

Edwards, California 93523-0273

H-2501

9. SPONSORING/MONITORING AGENCY NAME(S) AND ADDRESS(ES)

10. SPONSORING/MONITORING

AGENCY REPORT NUMBER

National Aeronautics and Space Administration

Washington, DC 20546-0001

NASA/TM-2002-210731

11. SUPPLEMENTARY NOTES

Also presented at the AIAA Modeling and Simlation Technologies conference at Monterey, CA,

August 5-8, 2002

\begin{tabular}{l|l}
\hline 12a. DISTRIBUTION/AVAILABILITY STATEMENT & 12b. DISTRIBUTION CODE \\
Unclassified-Unlimited & \\
Subject Category 05 & \\
This report is available at http:/www.dfrc.nasa.gov/DTRS/ &
\end{tabular}

13. ABSTRACT (Maximum 200 words)

NASA Dryden Flight Research Center uses its six-degrees-of-freedom (6-DOF) fixed-base simulations for mission control room training to improve flight safety and operations. This concept is applied to numerous flight projects such as the F-18 High Alpha Research Vehicle (HARV), the F-15 Intelligent Flight Control System (IFCS), the X-38 Actuator Control Test (XACT), and X-43A (Hyper-X). The Dryden 6-DOF simulations are typically used through various stages of a project, from design to ground tests. The roles of these simulations have expanded to support control room training, reinforcing flight safety by building control room staff proficiency. Real-time telemetry, radar, and video data are generated from flight vehicle simulation models. These data are used to drive the control room displays. Nominal static values are used to complete information where appropriate. Audio communication is also an integral part of training sessions. This simulation capability is used to train control room personnel and flight crew for nominal missions and emergency situations. Such training sessions are also opportunities to refine flight cards and control room display pages, exercise emergency procedures, and practice control room setup for the day of flight. This paper describes this technology as it is used in the X-43A and F-15 IFCS and XACT projects.

14. SUBJECT TERMS

Computer programs, flight safety, flight training, integrated mission control center, simulation

17. SECURITY CLASSIFICATION
OF REPORT
Unclassified

NSN 7540-01-280-5500

\begin{tabular}{l|l}
$\begin{array}{l}\text { 18. SECURITY CLASSIFICATION } \\
\text { OF THIS PAGE }\end{array}$ & $\begin{array}{l}\text { 19. SECURITY CLASSIFICATION } \\
\text { OF ABSTRACT } \\
\text { Unclassified }\end{array}$ \\
Unclassified
\end{tabular}

OF THIS PAGE
Unclassified

Unclassified

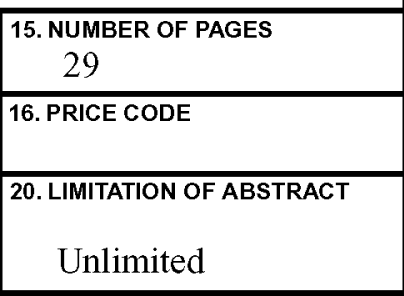

